\title{
Study on icebreaking performance of the Korea icebreaker ARAON in the arctic sea
}

\author{
Hyun-Soo Kim ${ }^{1}$, Chun-Ju Lee ${ }^{2}$, Kyung-Sik Choi ${ }^{3}$, Moon-Chan $\mathrm{Kim}^{4}$ \\ ${ }^{I}$ Department of Ship and Ocean System, Inha Technical College, Incheon, Korea \\ ${ }^{2}$ Korea Ocean Research \& Development Institute, Daejeon, Korea \\ ${ }^{3}$ Department of Naval Architecture and Ocean Systems Engineering, Korea Maritime University, Busan, Korea \\ ${ }^{4}$ Department of Naval Architecture and Ocean Engineering, Pusan National University, Busan, Korea
}

\begin{abstract}
A full-scale field trial in ice-covered sea is one of the most important tasks in the design of icebreaking ships. The first Korean icebreaking research vessel 'ARAON', after her delivery in late 2009, had a sea ice field trial in the Arctic Sea during July-August, 2010. This paper describes the test procedures and data analysis on the icebreaking performance of the IBRV ARAON. The data gathered from the icebreaking performance test in the Chukchi Sea and the Beaufort Sea during the Arctic voyage of ARAON includes the speed and engine power of the ship as well as sea ice thickness and strength data. The air temperature, wind speed and heading of the ship were also measured during each sea ice trial. The ARAON was designed to break $1 \mathrm{~m}$ thick level ice with a flexural strength of $630 \mathrm{kPa}$ at a continuous speed of $3 \mathrm{knots}$. She is registered as a KR POLAR 10 class ship. The principal dimensions of ARAON are $110 \mathrm{~m}, 19 \mathrm{~m}$ and $6.8 \mathrm{~m}$ in length, breadth and draft respectively. She is equipped with four $3,500 \mathrm{~kW}$ diesel-electric main engines and two Azipod type propulsion motors. Four sea ice trials were carried out to understand the relationship between the engine power and the ship speed, given the Arctic ice condition. The analysis shows that the ARAON was able to operate at $1.5 \mathrm{knots}$ in a $2.5 \mathrm{~m}$ thick medium ice floe condition with the engine power of $5 M W$, and the speed reached 3.1 knots at the same ice floe condition when the power increased to 6.6MW. She showed a good performance of speed in medium ice floe compared to the speed performance in level ice. More detailed analysis is summarized in this paper.
\end{abstract}

KEY WORDS: Ice field tests; Icebreaking research vessel; Icebreaking performance test; Full-scale field trial; Flexible ice strength.

\section{INTRODUCTION}

For understanding the icebreaking performance of a ship it is necessary to correctly estimate the ice resistance on the ship's hull during her ice field trials and to perform the proper tests for gathering sea ice data. After the delivery of the IBRV ARAON to her operator KOPRI (Korea Polar Research Institute) in late 2009, ARAON made sea ice trials twice in the Antarctic Sea (Jan. Feb. 2010) and in the Arctic Sea (July Aug. 2010, Fig. 1). Unfortunately the Arctic sea trial from July to August on 2010 was performed during time of melting ice in Arctic regions. It was carried out in the medium size ice floes rather than uniform level ice. In this paper, the Arctic voyage of ARAON and the icebreaking performance (i.e., measured speed vs. engine power) of ARAON in medium ice floe are described.

The icebreaker 'ARAON' is the first Korean research

Corresponding author: Moon-Chan Kim

e-mail:kmcprop@pusan.ac.kr icebreaker and was built by Hanjin Heavy Industries \& Construction Co. Ltd. Another mission of the ARAON was for a year-round transportation of cargos and personnel to the Korean science stations in the Antarctica (King Sejong St. and Jangbogo St.). As shown in Table 1, the principal particulars of ARAON are 110, 19 and $6.8 m$ in length, width and draft, respectively. She is equipped with four $3,500 \mathrm{~kW}$ diesel-electric main engines and two Azipod type propulsion motors.

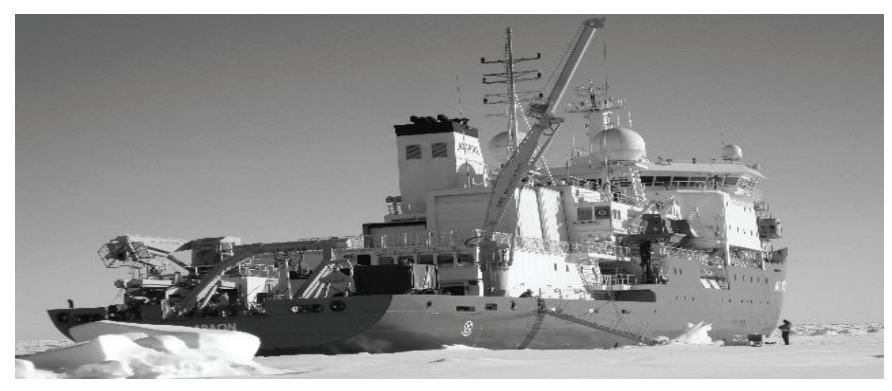

Fig. 1 ARAON in the arctic Sea. 
Table 1 Principal particulars of the ARAON.

\begin{tabular}{|l|l|}
\hline Length, O. A. $(\mathrm{m})$ & 111.0 \\
\hline Length, B. P. $(\mathrm{m})$ & 95.0 \\
\hline Beam, Maximum WL $(\mathrm{m})$ & 19.0 \\
\hline Design Draft $(\mathrm{m})$ & 6.8 \\
\hline Summer Max. Draft $(\mathrm{m})$ & 7.6 \\
\hline Gross Tonnage & 7,487 \\
\hline Propulsion Motors $(\mathrm{kW})$ & Aquamaster $2 \times 5,000$ \\
\hline Main Power Engines $(\mathrm{kW})$ & $\begin{array}{l}\text { MAN B\&W 7L32/40 } \\
\text { Diesel-electric 4 } 4 \text { 3,500 }\end{array}$ \\
\hline Speed $(\mathrm{knots}$, at 7,500kW) & 16.0 \\
\hline No. of Crew and Scientists & 85 \\
\hline $\begin{array}{l}\text { Operation Range } \\
\text { (naut. miles) }\end{array}$ & 20,000 \\
\hline Ship Class & Korean Register PL10 \\
\hline $\begin{array}{l}\text { Ice Performances } \\
\text { (Design Target) }\end{array}$ & $\begin{array}{l}\text { Speed 3knots in 1 } \mathrm{m} \text { level } \\
\text { ice with flexural strength } \\
\text { of not less than 630 } \mathrm{kPa}\end{array}$ \\
\hline
\end{tabular}

The ARAON was designed to break $1.0 \mathrm{~m}$ thick level ice at a speed of 3 knots. After her delivery in late 2009, she has been taking on important roles for two consecutive years in the Arctic and in the Antarctic seas.

A few publications have been implemented on the field trials using icebreakers. Michailidis and Murdey (1981) performed an ice trial in Lake Melville using a medium size icebreaker, the CCGS Franklin (displacement of 8,000tons and a total shaft power of $11,000 \mathrm{~kW}$ ). They analyzed the ship speed vs. power relation in a broken channel, in level ice with various different thicknesses, in pack ice and also in an open sea. They compared measured data with those from the model test. They also carried out a turning test in ice and compared the results with those from radar signal.

The first towed resistance test of the icebreaker, USCGC Mobile Bay was conducted by Zahn et al. (1987) on Green Bay in Lake Superior. The Mobile Bay has dimensions of $39.6 \mathrm{~m}$ in waterline length, $10.4 \mathrm{~m}$ in breadth and $3.66 \mathrm{~m}$ in draft. The engine power of Mobile Bay was $1,860 \mathrm{~kW}$ (2,500HP). The Mobile Bay was towed by a steel towline connected from the USCGC Mackinaw in unbroken level ice. A total of 17 towed resistance tests and 31 self propulsion tests were performed. The full-scale thrust deduction, wake fraction and quasi-propulsive efficiency were estimated from the model test data.

Subsequently, the U.S. Coast Guard conducted a series of ice trials of the icebreaking research vessel, Nathaniel B. Palmer during the winter of the 1992 Antarctic voyage. The results were published by Schultz et al. (1994). The Nathaniel B. Palmer was $85.3 m, 18.3 m, 6.7 m$ in length, breadth and draft respectively. The displacement of Nathaniel B. Palmer was 6,500ton and the engine power was $9,485 \mathrm{~kW}(12,700 \mathrm{SHP})$. It was classed as ABS Ice Class A2 and was designed for continuous icebreaking in $0.9 m$ thick first year level ice at $3 k n o t s$. The performance in level ice and in a broken ice channel and also the ramming and turning performance were evaluated.
Several ice performance tests of the USCGC HEALY were conducted by Sodhi et al. (2001). The tests were performed in Baffin Bay under various ice conditions. Riska et al. (2001) reported an ice performance test of the Swedish icebreaker, Tor Viking II in the northernmost Baltic Sea.

Recently, Belyashov et al. (2008) published ice field tests in the Kara Sea. A multipurpose icebreaking vessel, Yury Topchev was used for ice trials. Yury Topchev is $84.4 m$ in length, $19 \mathrm{~m}$ in breadth and $8 \mathrm{~m}$ in draft and it has a DWT of 3,800 tons and a power of $20,000 \mathrm{~kW}$ power. The design speed for icebreaking performance was $2 \mathrm{knots}$ in $1.5 \mathrm{~m}$ level ice with a $20 \mathrm{~cm}$ snow depth and a $550 \mathrm{kPa}$ flexural strength. The speed and power relationship were discussed in their publication.

As mentioned, the first ice trial for the newly built ARAON was conducted by Russian scientists in the Antarctic Sea (Jan. Feb. 2010) to investigate the ice performance of the ARAON (Likhomanov, 2010).

\section{ICE FIELD TRIAL SITE}

ARAON's ice field trials were performed in the Chukchi Sea and Beaufort Sea area during the summer season (July and Aug.) of 2010. The sea ice in this area consists of mostly pack ice with varying concentrations, and some hummocks and medium ice floes in late July and early August. There was some old ice but most of the sea ice was first year ice that was rapidly melting away. The structure of the sea was not strong and pack ice was fully distributed around the ship according to the wind and current. Due to so many scattered puddles, uniform level ice was very difficult to find.

The field test site for measuring sea ice properties was selected according to the availability of large and flat medium ice floes for the ice trial of ARAON. Because of the warm weather and low visibility, it was very difficult to find an medium ice floe large enough for the field trial. In order to perform a proper ice trial test, it was necessary to find an medium ice floe of which the size was about 2.5 to 3 times the length and 1.5 to 2 times the width of ARAON. With the help of a helicopter pilot and ice navigators onboard, four field test sites were selected. Table 2 summarizes the locations of the four test sites and the size of the medium ice floes used for the ice field trials. Fig. 2 shows ARAON's navigation route and the location of the field test sites in the Arctic Sea.

The first field trial site (July 20,2010) was selected on an medium ice floe with the size of $130 \mathrm{~m} \times 100 \mathrm{~m}$ and the mean ice thickness was $1.1 \mathrm{~m}$. Ice concentration was estimated to be $7 / 10 \sim 8 / 10$ and part of this medium ice floe was believed to be multiple layers of old ice. The second field test (Aug. 3, 2010) was performed on an medium ice floe with the size of $200 \mathrm{~m} \times 80 \mathrm{~m}$, and the mean ice thickness was approximately $2.22 \mathrm{~m}$. The ice concentration was estimated to be 7/10 8/10 and part of this medium ice floe was believed to be multiple layers of old ice. Several ice cores were extracted from the medium ice floe at locations of 0,80 and $160 \mathrm{~m}$. 
The third field test (Aug. 4, 2010) was performed near the second test site with an medium ice floe the size of $280 \mathrm{~m} \times$ $100 \mathrm{~m}$, and the mean ice thickness was approximately $1.88 \mathrm{~m}$. Ice concentration was estimated to be 7/10 8/10 and this medium ice floe was believed to be second year ice and had nearly a uniform thickness. Ice cores at 0,100 and $150 \mathrm{~m}$ locations were extracted to measure sea ice properties.

The fourth field test (Aug. 5, 2010) was performed at the northern most location near $78^{\circ} \mathrm{N}$. The size of the medium ice floe was $300 \mathrm{~m} \times 110 \mathrm{~m}$ and the mean ice thickness was approximately $2.46 \mathrm{~m}$. The ice concentration was estimated to be 9/10 10/10. Cores from 0,100 and $200 \mathrm{~m}$ locations were extracted. The size of the puddles on the medium ice floe was small and multiple layers of ice were stacked in the form of rubble ice. Ice thickness was not uniform.

As shown in Table 2, the length of the medium ice floe at test site \#1 is one and half times the length of ARAON. The width of the medium ice floe at test site \#2 is 4 times the vessel's breadth. The small area size of the first and second medium ice floes made it very difficult for the ARAON to carry out a proper icebreaking performance test. The third (\#3) and fourth (\#4) medium ice floes are not large enough; however, they are acceptable to be used for the icebreaking performance test along the marked track. It is believed that two times the ship length is long enough for the icebreaking performance test.

Table 2 Location of the field test sites and the size of medium ice floes.

\begin{tabular}{|c|c|c|c|c|}
\hline \multirow{2}{*}{$\begin{array}{c}\text { Test Number } \\
\text { and Test Date }\end{array}$} & \multicolumn{2}{|c|}{$\begin{array}{c}\text { Location of the } \\
\text { Test Site }\end{array}$} & \multicolumn{2}{c|}{ Ice Floe Size } \\
\cline { 2 - 5 } & Latitude & Longitude & Length & Width \\
\hline$\# 1$ (July 20) & $73^{\circ} 02 \mathrm{~N}$ & $168^{\circ} 26 \mathrm{~W}$ & $130 m$ & $100 m$ \\
\hline$\# 2$ (Aug. 3) & $77^{\circ} 01 \mathrm{~N}$ & $159^{\circ} 56 \mathrm{~W}$ & $200 m$ & $80 m$ \\
\hline$\# 3$ (Aug. 4) & $77^{\circ} 02 \mathrm{~N}$ & $159^{\circ} 49 \mathrm{~W}$ & $280 m$ & $100 m$ \\
\hline$\# 4$ (Aug. 5) & $77^{\circ} 59 \mathrm{~N}$ & $159^{\circ} 38 \mathrm{~W}$ & $300 m$ & $110 m$ \\
\hline
\end{tabular}

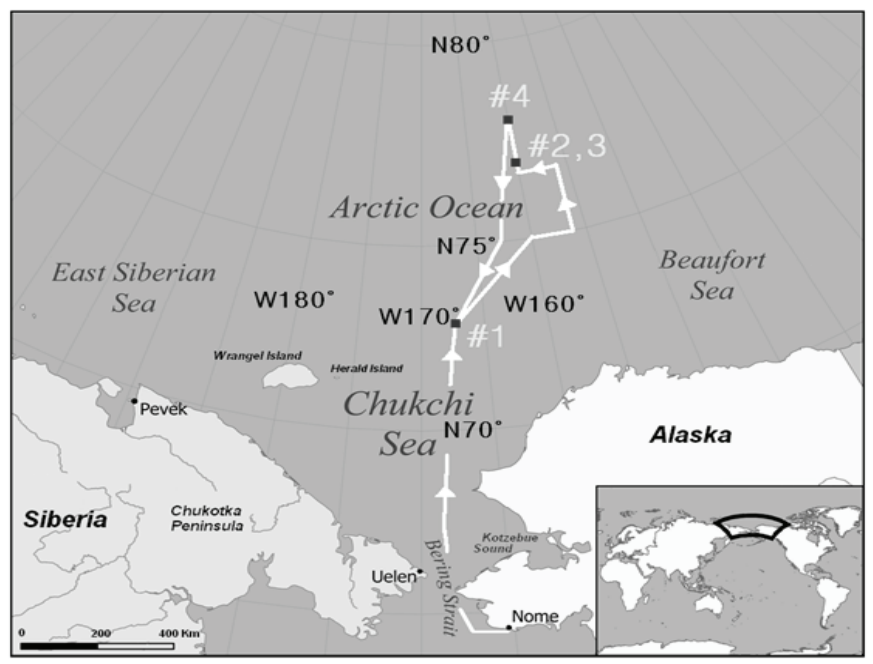

Fig. 2 Ice field trial sites in the Arctic Ocean. (July Aug. 2010)

\section{ICE TRIAL PROCEDURES AND INSTRUMENTATION}

Ice trial procedures measuring various ice properties and navigational information for ship performance are discussed in this paper. The data recorded from the icebreaking performance test during the Arctic voyage of ARAON includes the speed, engine power of the ship, air temperature, wind speed and the heading of the ship. Simultaneously, the ice information such as the ice thickness, compressive strength, the temperature of the ice, snow depth and free board of medium ice floe were measured in each ice field test.

The location of the ship and ship speed were measured by GPS signal. The engine power of the ship was recorded by a digital camera from the dynamic positioning system (DPS) of the ship. The wind speed and direction were recorded on an anemometer and the air temperature was also measured by a thermometer onboard the ship. The draft of the ship was measured by the draft measuring system. A gyro compass was used for measuring the ship's running course. An echo sounder was used for measuring the depth of the sea. The heeling angle was measured by a clinometer. Fig. 3 shows the various navigational apparatus onboard ARAON's bridge.
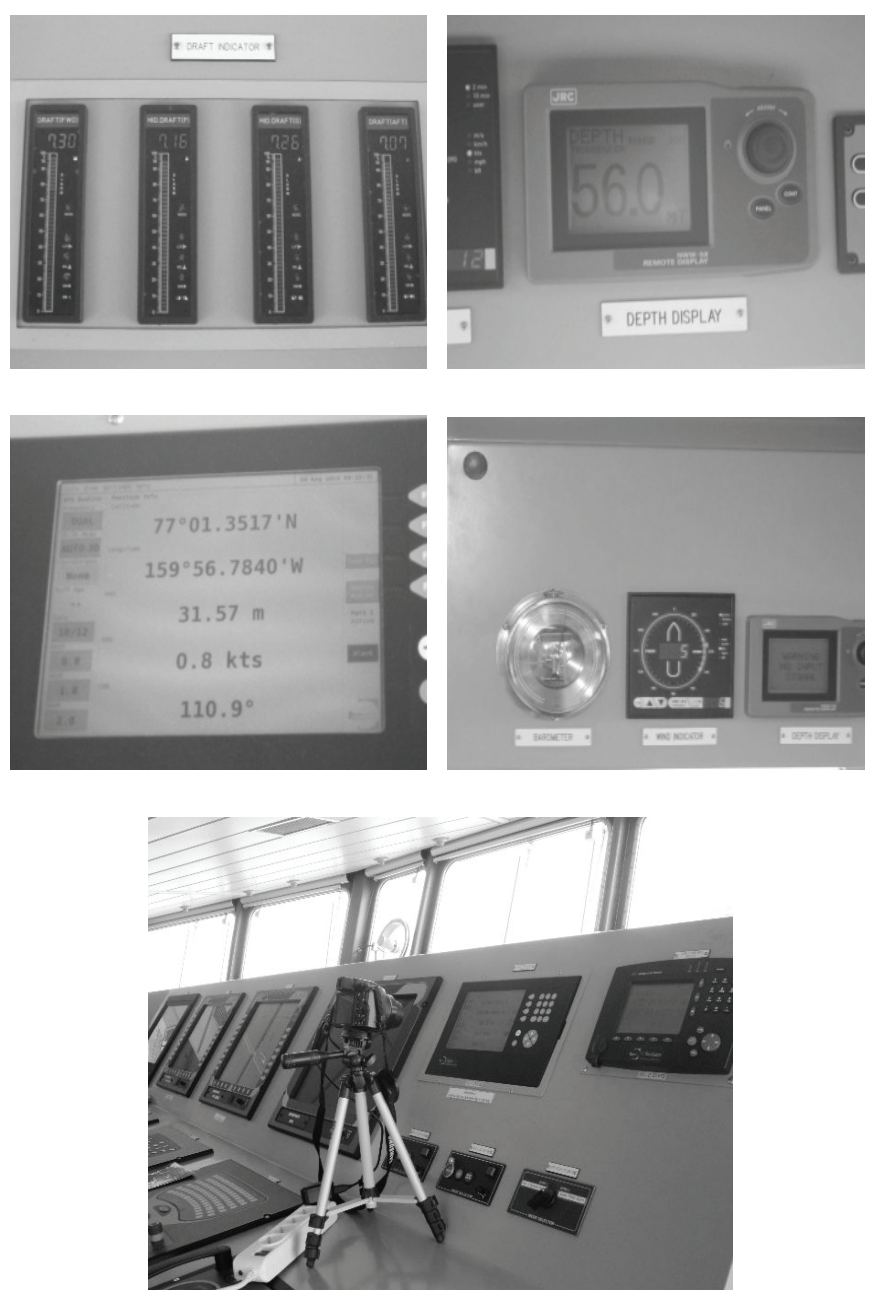

Fig. 3 Instruments for various navigational information. 
The material properties obtained through the ice field tests are as follows:

Ice thickness is the primary parameter among various ice properties. Sea ice thickness in the summer season changes significantly year to year depending on the prevailing weather condition. An auger connected to an electric motor can be used to make a $5 \mathrm{~cm}$ diameter hole and to measure the thickness of sea ice at a distance of every $10 \mathrm{~m}$ or $20 \mathrm{~m}$. Snow accumulation and the freeboard of sea ice were also recorded. The ice thickness at each test site was less than $2.0 \mathrm{~m}$ but sea ice was often superposed; hence the thickness sometimes exceeded $4 m$.

Core samples were extracted from the sea ice and a probe-type thermometer was used to measure temperatures at a distance of every $10 \mathrm{~cm} / 20 \mathrm{~cm}$ from the top surface to the bottom. The ice core was then cut into a $19 \mathrm{~cm}$ long specimen for a compression test. Before the compression test, the ice density was calculated by measuring the weight and the volume of each ice specimen using a portable spring gauge. The ice specimen after the compression test was placed into a small plastic box and stored under room temperature. One day later the ice specimen was completely melted and the ice salinity could then be measured by a portable salinity tester.

Ice strengths are also very important factors in consideration of the ice load and ice resistance on a ship's hull. The compressive strength of sea ice was measured using a compression tester onboard the ARAON. Well prepared ice specimens $(19 \mathrm{~cm}$ long and $7.5 \mathrm{~cm}$ diameter) were used in the measurement of ice compressive strengths. The flexural strength of sea ice can be estimated using Timco and O'Brien (1994) empirical formula such as in Equation (1). The compressive strength data and the flexural strength estimation are summarized in Table 3, including a list of other measured ice properties.

$$
\sigma_{f}=1.76 e^{-5.88 \sqrt{\gamma b}}
$$

where $\sigma_{f}$ : Flexural strength of sea ice in $\mathrm{MPa}$

$$
\gamma_{b} \text { : Non-dimensional brine volume }
$$

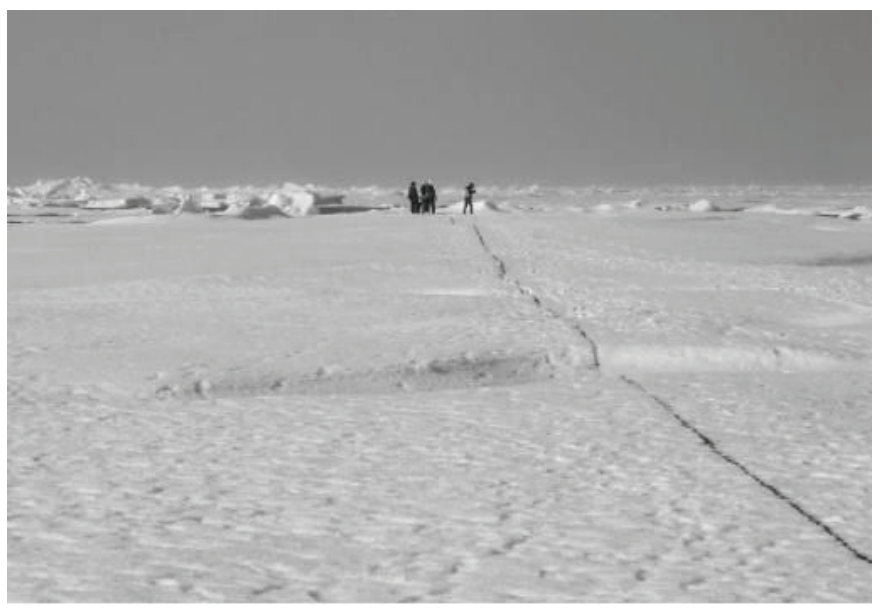

Fig. 4 Marked track line on ice floe at site \#1.
The video recording at several locations onboard the ARAON, such as the front forward/downward view from the bow and the port and starboard sides of the ship's hull were performed. The designated power level of the main engine was prepared and the speed test was then carried out. All the digital and analogue signals from the navigational apparatus, such as current location, running course, speed of the ship and torque of the propeller were recorded by digital cameras. The load exerted on the front port side hull was also measured by the hull stress monitoring system prepared by Korea Institute of Machinery \& Materials (KIMM), but these results and analysis are not included in this paper.

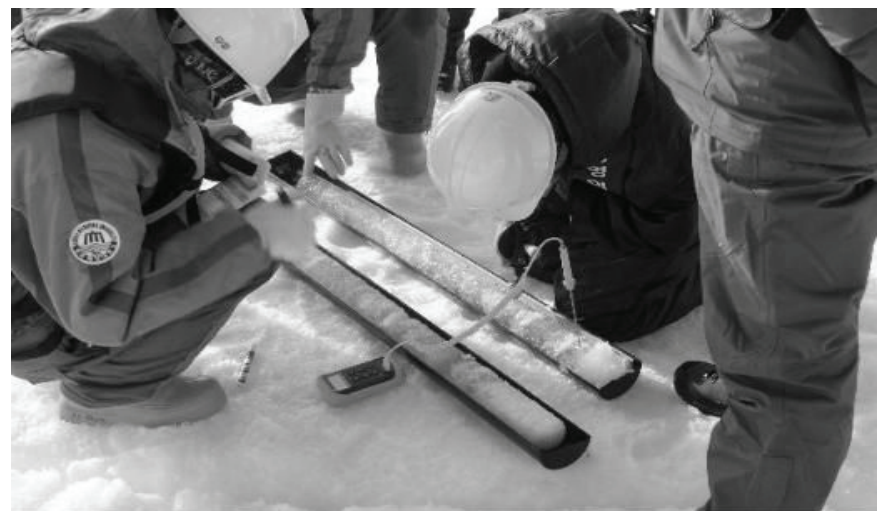

Fig. 5 Measuring temperature of ice specimen.

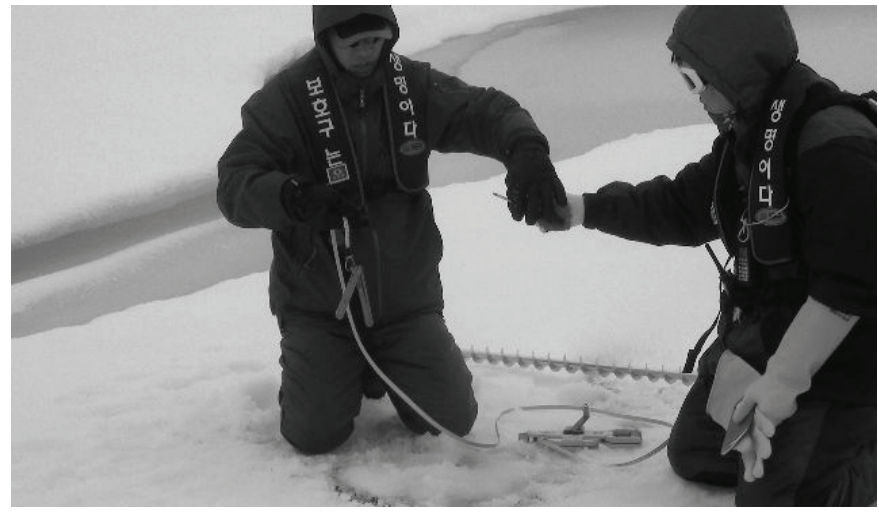

Fig. 6 Ice gauge to measure ice thickness.

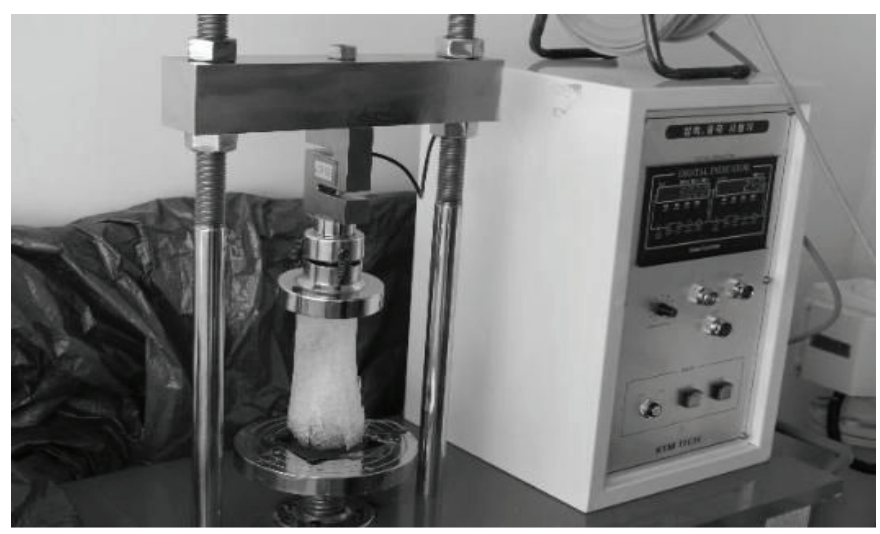

Fig. 7 Measuring compressive strength for ice specimen. 


\section{EVALUATION OF MEASURED DATA}

The results of the measured ice properties are summarized in Table 3, showing the marked distance and mean value of flexible strength, ice thickness, snow depth and free board of each ice floe. The equivalent ice thickness was calculated with one third of the snow depth added to the mean ice thickness.

The ice hole made by the ice auger device began to fill up with water if the hole passed through the ice floe. At certain times after the drilling, the hole of the medium ice floe filled up with the water but the ice was detected again underneath the medium ice floe, so another attempt was made to drill the ice. After drilling the ice, the ice thickness was measured. At certain times, two or three times the ice thickness was measured at the same points of medium ice floe. This means that the medium ice floe was superposed with small broken ice pieces and also that is the reason of why it has big free board compare to level ice condition. The ice thickness was used only for the pure thickness of the medium ice floe, with the exception of the superposed pack ice thickness.

Table 3 Summary of measured ice properties.

\begin{tabular}{|c|c|c|c|c|}
\hline Test No. & No.1 & No.2 & No.3 & No.4 \\
\hline $\begin{array}{c}\text { Marking } \\
\text { distance }\end{array}$ & 100 & 160 & 210 & 200 \\
\hline $\begin{array}{c}\text { Mean Flexible } \\
\text { strength }(\mathrm{kPa})\end{array}$ & 70 & 170 & 160 & 250 \\
\hline $\begin{array}{c}\text { Mean Ice } \\
\text { thickness }(\mathrm{m})\end{array}$ & 1.1 & 2.22 & 1.88 & 2.46 \\
\hline $\begin{array}{c}\text { Ice thickness } \\
\text { STD }(\mathrm{m})\end{array}$ & 0.45 & 0.52 & 0.48 & 0.86 \\
\hline $\begin{array}{c}\text { Mean snow } \\
\text { depth }(\mathrm{cm})\end{array}$ & 13 & 9.31 & 8 & 10 \\
\hline $\begin{array}{c}\text { Mean Free } \\
\text { Board }(\mathrm{cm})\end{array}$ & 48 & 28 & 25 & 34 \\
\hline $\begin{array}{c}\text { Free Board } \\
(\mathrm{cm})\end{array}$ & 9.3 & 10 & 4.8 & 14.1 \\
\hline $\begin{array}{c}\text { Equivalent Ice } \\
\text { thickness }(m)\end{array}$ & 1.14 & 2.25 & 1.91 & 2.49 \\
\hline
\end{tabular}

The free board depth in Table 3 was not too small compared to the free board depth of the level ice in Svalbard. It was less than $10 \mathrm{~cm}$ on April 2010 in the Arctic technical course (organized by DNV) but the free board depth in the Chukchi Sea was up to $48 \mathrm{~cm}$.

The flexible ice strength was calculated by Timco's method (1994) using temperature, density and salinity. The flexible strength of the test field was smaller than the design target. The highest value is $250 \mathrm{kPa}$ according to the analysis of Choi et al. (2011) The snow depth was around $10 \mathrm{~cm}$ but some points melted and then froze again, so distinguishing between snow and ice was not an easy task.

\section{RESULTS OF SPEED TRIAL}

The results of the speed trial are summarized in Table 4.
The marked distance, running time, GPS velocity, ice thickness and power of the engine are displayed in Table 4. The distance and ice thickness were measured values and the running time was recorded by a stop watch during the trial. The GPS velocity was recorded by a digital camera and the GPS velocity was rearranged by MS Excel software every 5 seconds after the trial. The mean GPS velocity was used in Table 4. Fig. 8 shows the time history of speed at $3^{\text {rd }}$ trial.

Table 4 Performance of ship in Sea trial.

\begin{tabular}{|c|c|c|c|c|c|}
\hline Test No. & No.1 & No.2 & No.3 & $\begin{array}{c}\text { No.4 } \\
\text { A }\end{array}$ & $\begin{array}{c}\text { No.4 } \\
\text { B }\end{array}$ \\
\hline $\begin{array}{c}\text { Marking } \\
\text { distance }\end{array}$ & 100 & 160 & 210 & 30 & 150 \\
\hline $\begin{array}{c}\text { Running Time } \\
(\mathrm{sec})\end{array}$ & 35 & 75 & 120 & 40 & 105 \\
\hline $\begin{array}{c}\text { Mean Velocity } \\
(\mathrm{m} / \mathrm{s})\end{array}$ & 2.86 & 2.46 & 1.75 & 1.00 & 1.43 \\
\hline $\begin{array}{c}\text { Mean Velocity } \\
(\mathrm{knots})\end{array}$ & 5.55 & 4.79 & 3.40 & 1.94 & 2.78 \\
\hline $\begin{array}{c}\text { Equivalent Ice } \\
\text { thickness }(m)\end{array}$ & 1.14 & 2.25 & 1.91 & 2.49 & 2.49 \\
\hline $\begin{array}{c}\text { Mean power } \\
(\mathrm{kW})\end{array}$ & 5,985 & 6,039 & 5,029 & 5,040 & 6,550 \\
\hline
\end{tabular}

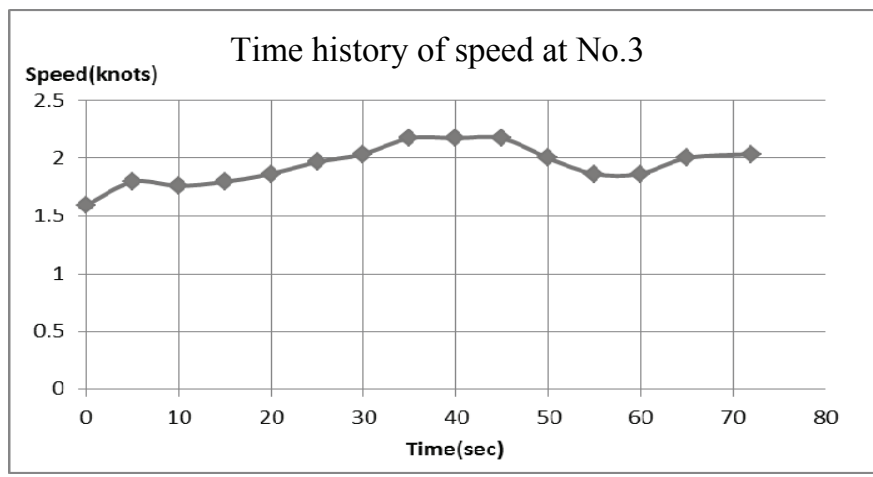

Fig. 8 Time history of speed on 3rd trial.

The power was set before the trial near the edge of medium ice floe. The starting point of trial was marked at the ice floe. The st.1(starting point of measuring) in Fig. 9 has a distance from the edge of ice floe. The distance between st.1 and the edge of the ice floe is about half of ship length. Authors expect that the distance might be reduced the effect of initial speed.

The power was determined by the captain's experience on the trial. The captain's recommendation of the power for the first and second trial was $6.0 \mathrm{MW}$ and for the third and fourth trial was $5.0 \mathrm{MW}$, but the power was changed during the fourth trial because the speed was decreasing compared to the expectation.

Fig. 10 shows the time history of power during the fourth trial. The changes of power history and transit range were plotted simultaneously. Only the steady state range of power was used for the analysis. Two results were obtained from the 4th trial according to the different power level, as shown in No. 4A and No. 4B in Table 4. 


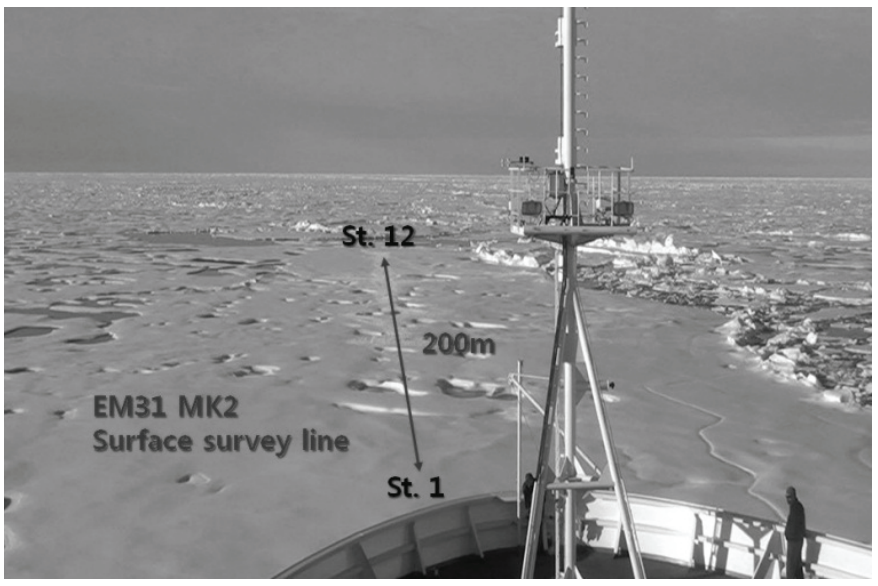

Fig. 9 Measuring distance on $3^{\text {rd }}$ ice floe

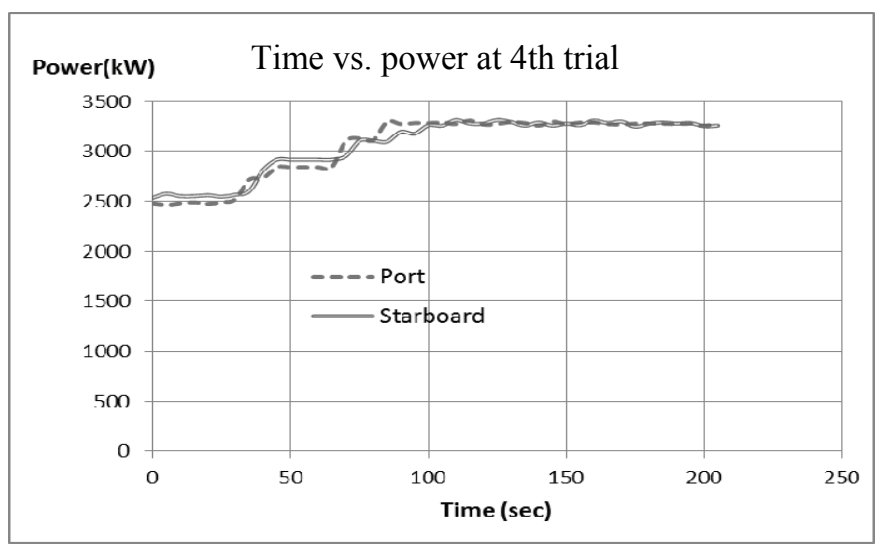

Fig. 10 Time history of speed on 4rd trial

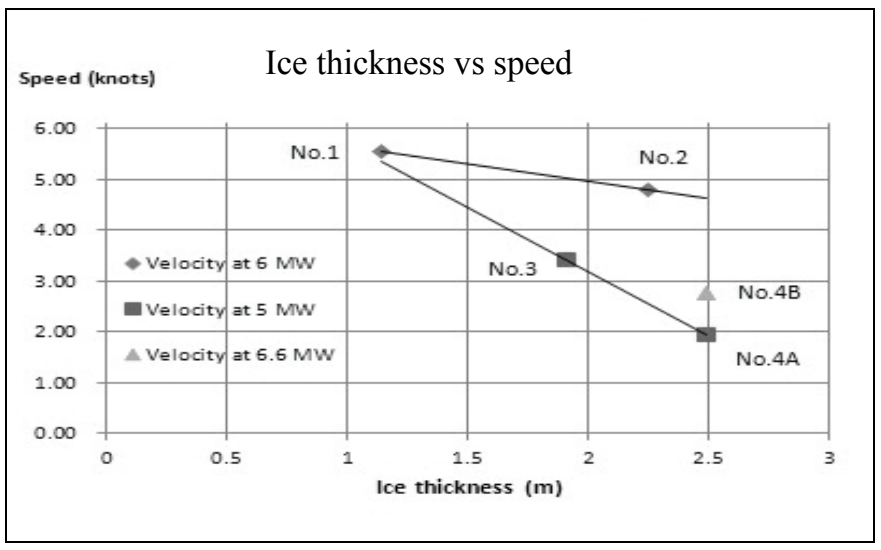

Fig. 11 Graph comparing ice thickness and speed.

Fig. 11 shows the performance of the ship by the GPS speed. The speed in the ice increases if the ice thickness decreases. The diamond signal and the rectangle show this phenomena when the power is constant. Another result shows that the speed increases if the power increases when the ice thickness is constant. The comparison of the rectangular and triangular symbols in the $2.5 \mathrm{~m}$ ice thickness shown in Fig. 11 explains the results. However, the speed at $6.0 \mathrm{MW}(4.6 \mathrm{knots})$ and speed at $6.6 \mathrm{MW}(2.8 \mathrm{knots})$ near the $2.5 \mathrm{~m}$ ice thickness shown in Fig. 11 contradict common sense because the speed decreases when the power increases. The accuracy of speed depends on the accuracy of GPS equipment. The Model of GPS equipment on ARAON is R4 Navigation System made by SAM Electronic (Korean maker). The position accuracy is $\pm 5 \mathrm{~m}$. The speed is calculated by the average in every 5 second. Those data have the accumulated error of GPS speed. To solve this problem, the direct distance calculation method (Robbin's method, Bomford, 1984) was used. The start point of latitude and longitude and end point of latitude and longitude are considered to correct the abnormal results.

\section{DIRECT DISTANCE CALCULATION}

The velocity of the ship can be calculated easily by the moving distance and measuring time during the official trial. Finding the exact time and moving distance during the trial is not easy because the entire system is not merged in one system in this ice sea trial. The GPS position and GPS time were used to obtain an exact time and distance. The result using the location of the starting and ending points has more accuracy compared to the method of GPS velocity at every second because there is a possibility for the GPS speed of every second to accumulate a small error during the trial. The simple calculation program of distance using two latitudes and longitudes was made by $\mathrm{C}++$ language. Fig. 12 shows the main frame of the program.

The logic of calculation follows Robbin's method. To check the accuracy of the program, the results were compared to the field test results (Kim et al., 2001). The error range is less than $0.01 \%$ as shown in Table 5 .

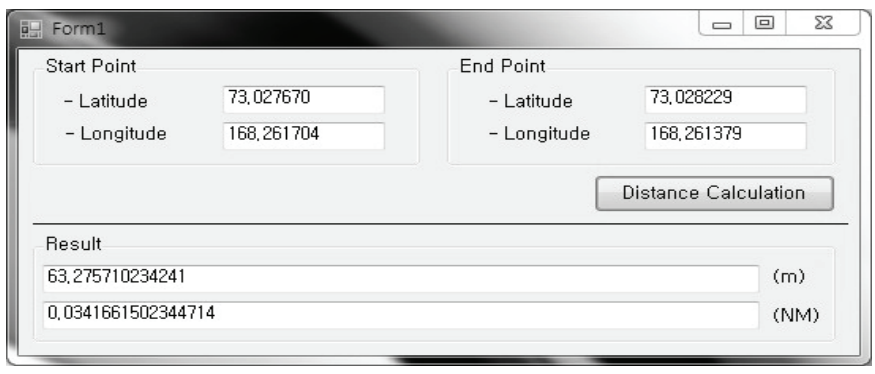

Fig. 12 Main frame of distance calculation program.

Table 5 Comparison of distance calculation between field test and program.

\begin{tabular}{|c|c|c|c|c|c|c|}
\hline \multirow{2}{*}{ No } & \multicolumn{2}{|c|}{ Start Point } & \multicolumn{2}{c|}{ End Point } & \multicolumn{2}{c|}{ Distance } \\
\cline { 2 - 7 } & Latitude & Longitude & Latitude & Longitude & Field(NM) & $\begin{array}{c}\text { Calculation } \\
\text { (NM) }\end{array}$ \\
\hline 1 & 34.382788 & 129.020621 & 34.398809 & 129.027255 & 1.0144873 & 1.0143309 \\
\hline 2 & 34.406735 & 129.030732 & 34.422725 & 129.037276 & 1.0112883 & 1.0111102 \\
\hline 3 & 34.427397 & 129.039059 & 34.443474 & 129.045368 & 1.0125905 & 1.0123747 \\
\hline 4 & 34.497440 & 129.035917 & 34.514192 & 129.036222 & 1.0034324 & 1.0035289 \\
\hline 5 & 34.519243 & 129.036998 & 34.535549 & 129.042088 & 1.0086867 & 1.0086283 \\
\hline 6 & 34.539014 & 129.043173 & 34.555273 & 129.048490 & 1.0088389 & 1.0087579 \\
\hline 7 & 34.559443 & 129.049726 & 34.575896 & 129.054226 & 1.0103429 & 1.0103129 \\
\hline 8 & 34.582309 & 129.056157 & 34.598451 & 129.061790 & 1.0063146 & 1.0061737 \\
\hline 9 & 34.603600 & 129.063075 & 34.620110 & 129.067330 & 1.0110208 & 1.0110385 \\
\hline 10 & 34.574102 & 128.822724 & 34.588751 & 128.833102 & 1.0169865 & 1.0164028 \\
\hline
\end{tabular}


Table 6 Distance calculation using program.

\begin{tabular}{|c|c|c|c|c|c|r|r|r|}
\hline & \multicolumn{2}{|c|}{ Start Point } & \multicolumn{2}{c|}{ End Point } & Distance & \multirow{2}{*}{ time } & \multicolumn{2}{c|}{ Velocity } \\
\cline { 1 - 3 } \cline { 8 - 9 } & Latitude & Longitude & Latitude & Longitude & Program(m) & & m/s & Knots \\
\hline 1 & 73.027670 & 168.261704 & 73.028229 & 168.261379 & 63.275710 & 32 & 1.97737 & 3.84402 \\
\hline 2 & 77.013660 & 159.441388 & 77.012614 & 159.442738 & 121.586363 & 75 & 1.62115 & 3.15154 \\
\hline 3 & 77.028389 & 159.494025 & 77.029412 & 159.492329 & 121.858344 & 90 & 1.35398 & 2.63216 \\
\hline 4A & 77.591612 & 159.379651 & 77.591751 & 159.378616 & 29.282800 & 37 & 0.79143 & 1.53854 \\
\hline 4B & 77.592297 & 159.376362 & 77.593188 & 159.373587 & 119.695800 & 75 & 1.59594 & 3.10253 \\
\hline
\end{tabular}

The trial results of ARAON were calculated by the program as shown Table 6 . The marking distances in Table 4 are larger than the running distance in Table 6 because the available running distance is selected before the ice breaking by crashing. The No.1 field is severe because the entire length of the ice is small and the No. 4 ice field is also severe because it transits the power during the test, thus separating the total running distance into two distances. Another difference in the calculation of distance is the use of a GPS signal for start and end points, except for all of the middle locations of GPS. This means that the trajectory of the ship is a straight line from the start to the end point.

The velocity was also recalculated using the distance from the program and time. The relations among speed, power and ice thickness are shown in Fig. 13.

The results in Fig. 13 differ from the results in Fig. 11. Fig. 13 follows common sense and satisfies the relations of speed, power and ice thickness. The interpolation line of the rectangular symbol and the extrapolation line of the diamond symbol cross each other at one point $(1.35 \mathrm{~m}$ ice thickness in Fig. 13 approximately). This means that the power and speed do not follow common sense if the ice thickness is lower than the cross point but the connection line between No.3 and No. 4A come from the extrapolation value of the trial results at $5 \mathrm{MW}$ power; therefore, the value of ice thickness lower than $1.9 \mathrm{~m}$ at $5 \mathrm{MW}$ power has small reliability. These results are also due to the different ice breaking phenomenon of each ice sheet. Soft medium ice floe cuts or tears rather than breaks in the sea trial because the ice is not level ice and is not fixed as a rigid body, moving to the void space of the sea in the heavy pack ice. Fig. 13 shows that it is possible to operate ARAON at 1.5 knots in $2.5 \mathrm{~m}$ ice thickness with $5 \mathrm{MW}$ engine power when the strength of the medium ice floe is $250 \mathrm{kPa}$. The speed is $3.1 \mathrm{knots}$ at the same ice condition if the power increases to $6.6 \mathrm{MW}$.

The analysis result of the ice sea trial shows the relation between the ice thickness, ice strength, ship speed and power of the engine. It is possible to operate ARAON at $1.5 \mathrm{knots}$ in $2.5 \mathrm{~m}$ ice thickness with $5 \mathrm{MW}$ engine power when the strength of the medium ice floe is $250 \mathrm{kPa}$. The speed reaches 3.1 knots at the same ice condition if the power increases to $6.6 \mathrm{MW}$. She shows good performance compared to the design target (3knots in $1.0 \mathrm{~m}$ level ice and $630 \mathrm{kPa}$ of flexible strength) but this is due to the different ice types and low flexible ice strength. More detailed analysis results were discussed in this paper.

The lines in Fig. 11 and Fig. 13 are not interpolation and extrapolation values. It shows just trends in same powers. It's very difficult to say the performance in other ice thickness of Fig. 11 and Fig. 13 except measured points itself because the strength of each ice floe is very weak and has big difference each other. Results in every measuring points give good information of performance.

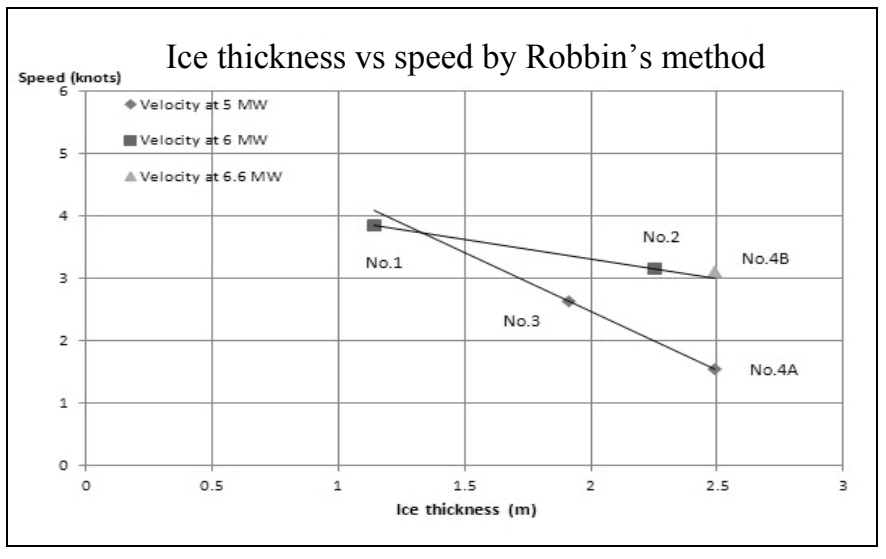

Fig. 13 Performance of ship using Robbin's method.

\section{DISCUSSION}

Fig. 14 shows the Sea trial results in the Antarctic by Lee et al. (2010) The speed is 3knots at $1.0 \mathrm{~m}$ ice thickness, $630 \mathrm{kPa}$ strength and $6.8 \mathrm{~m}$ draft. The results are derived from the measurements in the Antarctic and were analyzed for the equivalent ice flexible strength properties such as $630 \mathrm{kpa}$ and full power of $10 \mathrm{MW}$.

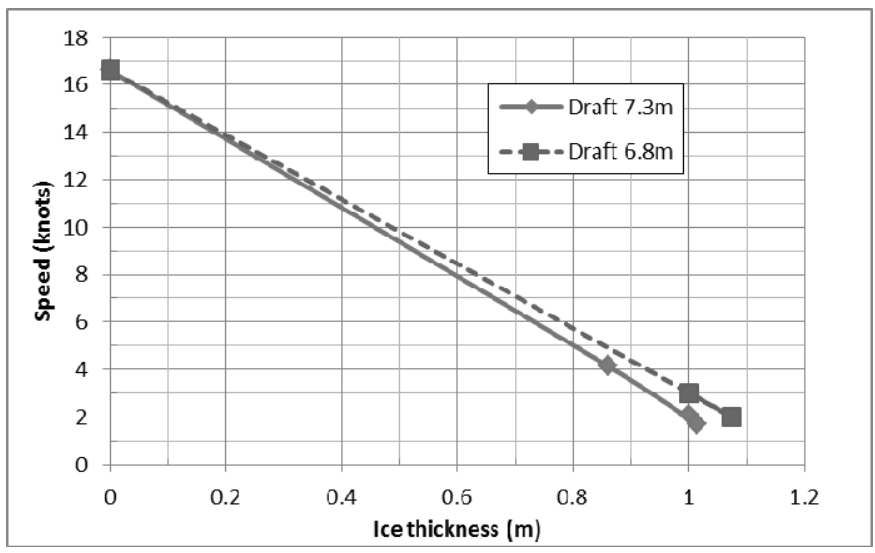

Fig. 14 Ice Sea trial results in Antarctic

The speed performances in the Antarctic were inferior to those of the results in the Arctic region. There are several reasons for this. The tried medium ice floe in the Arctic is not level ice so the ice strength is less than the design target and also the condition around the medium ice floe is not constrained as it is for level ice. The accuracy of the sea trial measurement in the Arctic is not systematic. The most important difference is the phenomena of ice breakings. The breaking shape near the bow differed compared to the shape of the model test in level ice. The breaking ice piece in the Arctic trial did not follow the bow shape and the bow made a crack in the ice floe in front of the ship. This caused ice breaking by crushing. Even considering this inaccuracy, the procedure of the sea trial is proven and the results are reliable in the relation between the ice thickness, strength, speed and power. 


\section{CONCLUSION}

The icebreaking research vessel 'ARAON' had a sea ice field trial in the Arctic Sea during July-August, 2010. Test procedures and data analysis on the icebreaking performance of the IBRV ARAON were described in this paper. The data gathered during the Arctic voyage of ARAON include speed, engine power of the ship as well as sea ice thickness and strength data. Air temperature, wind speed and the heading of the ship were also measured during each sea ice trial.

Four sea ice trials were carried out to understand the relationship between the engine power and the ship speed given the Arctic ice conditions. The analysis shows that ARAON was able to operate at 1.5 knots in a $2.5 \mathrm{~m}$ thick medium ice floe condition with the engine power of $5 \mathrm{MW}$ and the speed reached 3.1knots at the same ice floe condition when the power increased to $6.6 \mathrm{MW}$. She showed a good performance of speed in medium ice floe compared to the speed performance in level ice.

\section{ACKNOWLEDGMENTS}

This paper is part of "Development of the Safe Operation Methodology of Ice-class Vessel at Arctic Sea Route and the Cryogenic Evaluation Techniques for the Ice Performance (Grant No. 10033640)" supported by the Ministry of Knowledge and Economy, Korea. Financial support through the Industrial Strategic Technology Development Program (Grant No. PNS133B) is greatly acknowledged.

\section{REFERENCES}

Bomford, 4th edition, 1984. GEODESY, Oxford : Clarendon Press, ISBN : 019851946X.
Choi, K. Lee, C.J. Rim, C.W. and Kim, H.S., 2011. Strength Characteristics of Arctic Sea Ice from Ice Field Tests of the Icebreaking Research Vessel ARAON (to appear in Korean). Transactions of the Society of Naval Architects of Korea, 48(3), pp.254-259.

Kim, H.S. Park, G.I. and Ha, M.K., 2001. Computerized Measurement System of Ship Speed and Maneuvering Performance in Sea Trial, Journal of the society of naval architects of Korea, 38(3), pp.54-61.

Lee, C.J. Jeong, S.Y. Ahn, D.S. and Kim, H.S., 2010. The Ice Field Tests of ARAON in Arctic Ocean (in Korean). Proceeding of the Society of Naval Architects of Korea, Annual Autumn Meeting, Changwon, pp.134-140.

Likhomanov, V., 2010. Full-Scale Ice Trials of the Korean Research Icebreaker ARAON, Arctic and Antarctic Research Institute Russian Antarctic Expedition Report.

Michailidis, M. and Murdey, D.C., 1981. Performance of CCGS FRANKLIN in Lake Melville, 1980. Proceeding of the SNAME STAR Symposium, pp.311-322.

Riska, K. Leiviska, T. Nyman, T. Fransson, L. Lehtonen, J. Eronen, H. Backman, A., 2001. Ice performance of the Swedish multi-purpose icebreaker Tor Viking II. $P O A C^{\prime}$ 01.2, pp.849-866.

Schultz, L.A. Middleton, R.W. and Dai, R.Y.T., 1994. Operational Performance of the RV NATHANIEL B. PALMER. ICETECH '94, pp.1-26.

Sodhi, D. Griggs, D. and Tucker, W., 2001. Ice performance tests of USCGC Healy. POAC' 01, 2, pp.893-908

Timco, G.W. and O'Brien, S., 1994. Flexural Strength Equation for Sea Ice. Cold Regions Science and Technology, 22, pp.285-298.

Valery A. Belyashov, Alexandr V. Grozdov, Kirill E. Sazonov and Alexandr P. Tumashik, 2008. "Yury Topchev" and Vladislav Strizhov" Multipurpose Ice-breaking Vessels for Prirazlomnaya Platform Maintenance : Field and Model Tests. ICETECH 08-106-RF.

Zahn, P.B. Humphreys, D. and Phillips, L., 1987. Full-scale Towed Resistance Trials of the USCGC Mobile Bay in Uniform Level Ice. SNAME Transactions, 95, pp.45-77. 